Asian J. Med. Biol. Res. 2018, 4 (3), 233-241; doi: 10.3329/ajmbr.v4i3.38461

\author{
Asian Journal of \\ Medical and Biological Research \\ ISSN 2411-4472 (Print) 2412-5571 (Online) \\ www.ebupress.com/journal/ajmbr
}

\title{
Review \\ A review paper on the hazardous effect of plastic debris on marine biodiversity with some possible remedies
}

\author{
Md. Abul Hasnat ${ }^{1 *}$ and Mohammad Atikur Rahman ${ }^{2}$ \\ ${ }^{1}$ Department of Entomology, Faculty of Agriculture, Sher-e-Bangla Agricultural University, Sher-e-Bangla \\ Nagar, Dhaka, Bangladesh \\ ${ }^{2}$ Department of Ecology, Environment and Plant Science (DEEP), Stockholm University, Sweden \\ ${ }^{*}$ Corresponding author: Md. Abul Hasnat, Research Associate, Dept. of Entomology, Faculty of Agriculture, \\ Sher-e-Bangla Agricultural University, Sher-e-Bangla Nagar, Dhaka, Bangladesh. Phone: +8801763715284 ; E- \\ mail: mdha8565@student.su.se, takisumon01@gmail.com
}

Received: 07 September 2018/Accepted: 23 September 2018/ Published: 30 September 2018

\begin{abstract}
The consequences of plastic debris in the marine environment were reviewed, and possible solutions were presented. The extent of marine plastic debris-related problems surpasses many other marine problems, as plastics may be transported globally and no unaffected areas seem to exist. Many animal species are in risk, most commonly studied are the effects on marine mammals and seabirds. Marine plastic debris creates new concerns such as entanglement, ghost fishing, and impaction of digestive tracts in animals. It also increases the severity of already existing concerns such as transport, exposure and uptake of organic pollution, with reduced fitness and impaired reproduction and increased mortality rates as consequences. To alleviate the problems, reducing the extent of marine plastic pollution is critical. Possible methods were identified as collecting and incentivizing recycling of marine plastic debris; redirecting production from petroleum plastics to biodegradable varieties; increase public awareness to reduce marine littering; stricter enforcement of current legislation as well as implementation of stricter legislation and harsher penalties for breaking it.
\end{abstract}

Keywords: marine plastic debris; pollution; entanglement; ingestion; toxicity; plastic recycling

\begin{abstract}
1. Introduction
Plastic is one of the most versatile products in the world, and its integration into our everyday lives poses problems. Plastics are easy to manufacture, cheap and durable. This is what made plastic materials popular, but it is also the reason to that plastic pollution is now a growing concern. As only a minor part of the produced volumes of plastics are recycled, most of it will eventually end up in a landfill or in nature. In nature, a large part ends up in the oceans, where it has adverse effects on marine organisms. Knowledge is the key to any problem, and this report summarizes the knowledge of problems caused by plastic pollution in the marine environment.
\end{abstract}

\section{Background}

\subsection{Production of plastics}

Plastic is a relatively cheap, light and durable material. The production of plastic is increasing because of its advantages over other material for packaging and other wide range of applications. Plastics are synthetic organic polymers and may persist in the natural environment for over a century (Gorman, 1993). The yearly global plastic production is predicted to be slightly reduced in the coming years due to the global economic crisis and high price on oil as well as the increasing environmental awareness of the consumers. Global plastic production was estimated to $245 \mathrm{Mt}$ in 2008, which was decreased to $230 \mathrm{Mt}$ in 2009 (BIO Intelligence Service, 2011). During the past fifty years there's been a continual rise of plastic production (Figure 1) where EU accounted for 
25\% and China accounted for 15\% of total plastic production. By 1988 United States produced 30 million tons of plastic annually (O' Hara et al., 1988) which is a considerable amount. Plastics' properties and versatility makes it highly popular for everyday use.

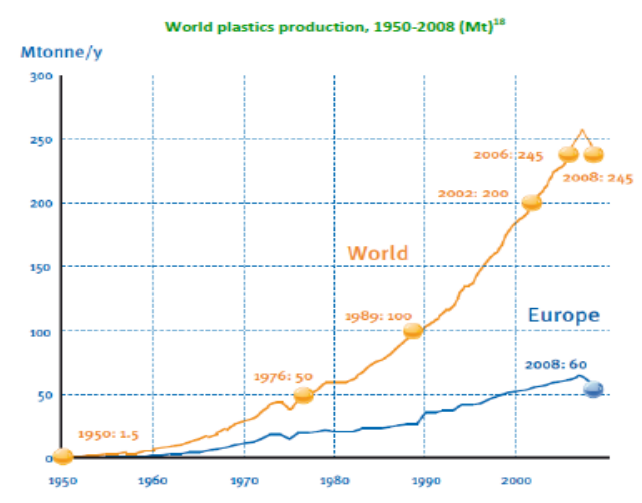

Figure 1. Global and European plastics production from 1950 to 2008, adapted from European Commission (2011). The graph includes thermoplastics, polyurethanes, thermosets, elastomers, adhesives, coatings, sealants and PP-fibers. Not included are PET-, PA- and polydactyl fibers.

Out of the global plastic production, $72 \%$ is consumed by four sectors: packaging, construction, automotive, and electronics/electrical equipment. The remainder is used in households, furniture, medical equipment, and in the agricultural sector.

Bio plastics are now being produced as an increasing demand for environmentally friendly alternatives to petroleum plastics have made them popular. There are two types of bio plastics: bio-based plastic derived from renewable resources and biodegradable plastics that degrade rapidly in the environment. In Europe, bio plastic consumption is estimated to around $0.1-0.2 \%$ of total European plastic consumption, but the global market for bio plastic is growing rapidly (European commission, 2011).

\subsection{Origins of marine plastic debris}

Marine plastic debris is an entirely anthropological induced problem that causes harm to the environment and marine organisms. The amount of marine plastic debris is not fully assessed, but studies show that $80 \%$ of marine plastic waste is from land based sources and 20\% from ocean based sources (Sheavly, 2005) identified some sources of marine plastic debris.

Major land based sources that were identified were:

- Storm water discharge, street garbage, landfill waste, forestry, agricultural and industrial waste, construction materials

- Combined Sewer Overflows (CSOs)

- Tourism-related litter at the coast: bottles, cigarette buts, packets, plastic toys

- Illegal dumping of domestic or industrial plastic waste

- Industrial activities

The major ocean based sources were:

- Commercial fishing: nylon nets, ropes, bait boxes, traps

- Recreational boaters

- Merchant, military and research vessels

- Offshore oil and gas platforms, undersea exploration: drums, survey materials etc.

In 1975 the world fishing fleet alone dumped approximately 135,400 tons of plastic fishing gear and 23,600 tons of plastic packaging material into the sea (Cawthorn, 1989; DOC, 1990) and yearly figures are probably similar today. We are mostly paying attention to the plastic that can be seen by eye. There are, however, small plastic pellets and granules that cannot be visually detected by eye only and that can be the main threat to the marine environment. These are found in large quantities in the water and on beaches (Gregory, 1978, 1989; Shiber, 1979, 1982, 1987; Redford et al., 1997).

Small particles are discharged mainly through industrial waste, household waste and break-up of large plastics by grinding from rocks and sand (Eriksson and Burton, 2003). Small plastic fragments are also formed by wave 
action, oxidation and exposure of plastics to ultraviolet light (Gregory, 1978; Shiber, 1979; Redford et al., 1997). Their sizes vary from $2-6 \mathrm{~mm}$, (Gregory, 1977, 1978) and in some cases they can be in the nanometer size range. These small particles are more hazardous because they release toxic chemicals more easily, cannot be extracted easily and are thus expensive to remove from the water column.

United Nations Environmental program reported in 2005 that there are on average 13,000 pieces of plastic debris per square kilometer of ocean. Plastics are buoyant and can be dispersed and transported long distances by water currents and wind (Derraik, 2002; Sheavly, 2005). Large quantities of marine debris may be found along shorelines close to urban and industrial areas. Ambon Bay, Eastern Indonesia is an example of extreme marine plastic debris accumulation, where beach litter may cover as much as $90 \%$ of the upper shore line. (Uneputty and Evans, 1997).

Plastic debris from fishing activities is the dominating part of the debris in areas far away from urbanized areas (Derraik, 2002). There are two hotspots reported throughout the literature, where floating plastic debris density is exponentially higher than in other areas. In 1999, the abundance of plastic debris of north pacific central gyre was reported to be as high as 334,271 pieces $/ \mathrm{km}^{2}$ on average (Moore et al., 2001) and a survey in Ambon Bay, Eastern Indonesia conducted in 1994-95 resulted in the highest density of floating debris ever recorded, at more than 4 million plastic particles $/ \mathrm{km}^{2}$ (Uneputty and Evans, 1997). Several review articles have attempted to compare abundances in oceans, one of which is (Allsopp et al., 2006) (Table 1), who looked at eye sightings from ships and found that there was large variance in marine plastic debris abundances.

Table 1. Abundances of floating marine debris in the world's oceans. Data collected by visual sighting from ships. Adapted from (Allsopp et al., 2006).

\begin{tabular}{|c|c|c|}
\hline Location and date & $\begin{array}{l}\text { Mean number of items of } \\
\text { debris per } \mathbf{k m}^{2}\end{array}$ & Reference \\
\hline West Spitsbergen, Arctic (2002) & $0-3$ & Barnes and Milner, 2005 \\
\hline North Atlantic, latitude $0^{\circ}$ to $50^{\circ} \mathrm{N}(2002)$ & $0-20$ & Barnes and Milner, 2005 \\
\hline English Channel (2002) & $10-100+$ & Barnes and Milner, 2005 \\
\hline Mediterranean & Density in the order of: & Aliani et al., 2003 \\
\hline $\begin{array}{l}(1997) \\
(2000)\end{array}$ & $\begin{array}{l}1.5-25 \\
1.5-3\end{array}$ & \\
\hline NE Pacific, latitude < $20^{\circ} \mathrm{N}(1986-91)$ & 1.8 & Thiel et al., 2003 \\
\hline NE Pacific, latitude $20^{\circ} \mathrm{N}$ to $40^{\circ} \mathrm{N}(1986-91)$ & 1 & Thiel et al., 2003 \\
\hline NE Pacific, latitude $>40^{\circ} \mathrm{N}(1986-91)$ & 1 & Thiel et al., 2003 \\
\hline NW Pacific, latitude < 20N (1986-91) & 0.25 & Thiel et al., 2003 \\
\hline NW Pacific, latitude $20^{\circ} \mathrm{N}$ to $40^{\circ} \mathrm{N}(1986-91)$ & 0.8 & Thiel et al., 2003 \\
\hline NW Pacific, latitude $>40^{\circ} \mathrm{N}(1986-91)$ & 0.2 & Thiel et al., 2003 \\
\hline Southern Atlantic, latitude $50^{\circ} \mathrm{S}$ to $0^{\circ} \mathrm{S}(2002)$ & $0-10$ & Barnes and Milner, 2005 \\
\hline Ambon Bay, Indonesia (1994/5) & $>4$ per $\mathrm{m}^{2}$ & Uneputty and Evans, 1997 \\
\hline \multicolumn{3}{|l|}{ Figure is for the worst affected areas } \\
\hline Chile, coastal waters, latitude $20^{\circ} \mathrm{S}$ to $40^{\circ} \mathrm{S}$ (2002) & $1-36$ & Thiel et al., 2003 \\
\hline Chile, coastal waters, latitude $40^{\circ} \mathrm{S}$ to $50^{\circ} \mathrm{S}$ (2002) & $<1$ & Thiel et al., 2003 \\
\hline Southern Ocean, near Antarctic Peninsula & $0-1$ & Barnes and Milner, 2005 \\
\hline Southern Ocean, Drakes Passage & $0-3$ & Barnes and Milner, 2005 \\
\hline
\end{tabular}

\subsection{Plastics in the environment - breakdown and decomposition}

Most plastics are non-biodegradable and persist in the nature for long periods of time. Plastic bags are made up of polyethylene and extensively used throughout the world. Ultraviolet radiation and high temperature could split polyethylene structures and turn it into small pieces and then small microscopic granules. Lobelle and Cunliff (2011) did an experiment to study biodegradation of marine plastic debris. They collected plastic material from the marine environment and submerged it in salt water under controlled laboratory conditions. Microbial biofilm formation was observed that induced lower hydrophobicity and lowered buoyancy, but no degradation was seen in the sample. There is no thus no evidence or indication of microbial degradation of plastic debris in the marine environment.

\subsection{Plastic ingestion by marine animals}

Plastic fragments can be mistaken for food items or accidently consumed during foraging. Such problems have been reported for many different animals of several taxa, including many species of seabirds (Blight and Burger, 1997), at least 26 species of toothed whales (Baird and Hooker, 2000; Secchi and Zarzur, 1999), sea lions 
(Raum-Suryan et al., 2009), sea cucumbers (Graham and Thompson, 2008), sea turtles (Tomás et al., 2000; Bjorndal et al., 1994) and planktivorous fish (Boerger et al., 2010).

The ingestion of plastic may be fatal if the digestive tract of an animal becomes impacted (Bjorndal, 1994). Other complications of plastic ingestion are toxic effects from plastic-carried contaminants such as reported for PCBs in Great Shearwaters, Puffinus gravis (Ryan et al., 1988a), lowered fitness due to reduced consumption rates derived from reduced storage volume and diminished feeding stimulus as shown in chicken (Ryan et al., 1988b) and adverse effects on the nutrient uptake, lowered steroid hormone levels, delayed ovulation and failed reproduction, as shown in seabirds by Azzarello and Van Vleet (1987).

The ingestion of plastics by seabirds depends on foraging techniques and prey type; Azzarello and Van Vleet (1987) found that planktivorous seabirds ingest higher amounts of plastic pellets than piscivores, as pellets more closely resemble the planktivorous seabirds preferred food items. In a study by Tomas et al., (2002), it was found that out of 54 illegally captured juvenile loggerhead sea turtles in the Mediterranean, $75.9 \%$ had plastic debris in their intestines, and that the volume of ingested debris was positively correlated to the size of the turtle. The study found no preferences regarding the consistency or color of the ingested plastics, and concluded that generalist predators such as the loggerhead sea turtle may therefore be more vulnerable to ingesting marine debris than specialist feeders (Tomas et al., 2002).

\subsection{Entanglement and ghost fishing}

Entanglement is a well-reported problem which has many adverse effects on marine life, some of which are drowning, strangling, reduced ability to catch food and escape predators, cut wounds, and reduced fitness due to increased energetic costs of movement (Raum-Suryan et al., 2009; Feldkamp et al., 1989; Laist, 1989). It is hard to estimate the amount of entangled animals as many species are rarely observed or die at sea (Raum-Suryan $e t$ al., 2009). Certain groups of animals seem to be the more affected by entanglement than others, among these are marine mammals, seabirds and sea turtles.

UNEP (1997) report that at least 267 marine animal species have been found entangled in marine plastic debris. A study by Moore et al., (2009) compiled data of entangled animals found on beaches in California and found that 31 species of birds, 9 species of marine mammals and 1 species of sea turtles had been found entangled during 2001-2005, most of which were entangled in fishing related equipment. An inventory of gannets (Sula bassana) in Helgoland, German Bight showed that out of the 23 dead or dying gannets found, $29 \%$ were entangled in net fragments (Schrey and Vauk, 1987). Additionally, from 313 in-air observations, at least $2.6 \%$ of flying gannets were entangled in fragments of fishing gear. Votier et al., (2011) found that the colonial seabird northern gannet (Morus bassanus) would build nests using plastic materials, using on average $470 \mathrm{~g}$ of plastic per nest, which added up to an estimated 18.8 tons of plastic in the studied colony of 40.000 nests. It was also judged that entanglement due to this nesting preference was unlikely to have population-wide effects, entangling only 525 individuals over eight years.

Steller's sea lions (Eumetopias jubatus) were surveyed in Alaska and British Columbia by Raum-Suryan et al. (2009), who found that 386 individuals, $0.26 \%$ of the population, was entangled or had ingested fishing gear that was still visible. Out of these individuals, $49 \%$ of the animals had entanglements around the neck (77\% had been embedded too deep in tissue to be identifiable), out of which plastic packing bands and rubber bands accounted for $84 \%$ of the total. The other $50 \%$ of the individuals had swallowed or become hooked in fishing gear; out of these animals, $80 \%$ had swallowed salmon fishery flashers or their hooks, and $12 \%$ had been caught in long line hooks.

As for ghost fishing, lost fishing gear may continue to catch fish and crustaceans. The likelihood for ghost fishing to occur is higher with passive tools such as traps and gillnets than with active tools such as seine nets and troll gear (Breen, 1990). As the material of fishing gear has moved from low-durability organic products to artificial products, the breakdown and disablement of the equipment is highly delayed (Breen, 1990). Trap fishing requires bait, which when a trap is lost consists of the carcasses of trapped animals; as the death of one animal lures more animals into the same deathtrap, the trap may continue to fish until it loses its function to do so by decaying (Breen, 1990). Lost fishing gear is not easy to quantify, as some of it is discarded or left on purpose and legislation such as MARPOL's Annex V prohibits disposal at sea. This means that the extent of this problem may very well be underestimated.

\subsection{Toxic effects of plastics}

Plastics are hydrophobic materials and will readily transport hydrophobic substances by sorption. Plastics that take up toxic hydrophobic substances can transport these contaminants to sediments or target organisms, where the contaminants may be released. 
Teuten et al. (2007) conducted a study where three plastics were contaminated with phenanthrene, comparing sorption rates to natural sediments. They found that plastics had a rate of sorption that greatly exceeded that of natural sediments, and that the plastics also had lower desorption rates. Furthermore, they found differences amongst the plastics, where polyethylene had a much higher uptake than polypropylene and polyvinyl chloride (PVC).

Teuten et al. (2007) also found that the lugworm Arenicola marina showed an accumulation of phenanthrene when adding phenanthrene-contaminated plastic to sediments at a plastic to sediment ratio of only 1:1.000.000 $(1 \mu \mathrm{g} / \mathrm{g})$, concluding that plastics may be an important pathway for the transport of hydrophobic substances to sediments.

Mato el al. (2001) measured hydrophobic contaminants in polypropylene on the coasts of Japan and found that PCBs, DDE and nonylphenols were adsorbed to polypropylene in comparable amounts to the amounts found adsorbed to suspended particles and bottom sediments. They then conducted an experiment, which showed that polypropylene pellets have PCBs and DDE adsorption coefficients of $10^{5}-10^{6}$ in seawater, meaning plastic pellets have a high accumulation potential for hydrophobic contaminants, supporting the findings of Teuten $e t$ al. (2007).

\subsection{Drifting plastics as a pathway for invasive species}

Invasive species is a major problem in marine conservation. Species spread and colonize new areas naturally, but as a result of human activities the ability and speed of spreading is increased (Bax et al., 2003). For example, ships unintentionally take up organisms in their ballast water which is then transported and released in remote areas, people intentionally plant species in areas where they are not indigenous, and finally, organisms may spread attached to floating marine debris. As plastics make up the majority of floating marine debris globally (Derraik, 2002), they contribute to the spatial distribution of non-indigenous species.

\section{Solutions}

\subsection{Plastic recycling}

The first idea that might spring to mind when it comes to solving the problem of marine plastic pollution is to clean the oceans of plastic debris mechanically, i.e., to "vacuum clean" the oceans like fishermen. Once a viable approach to collecting the plastic debris is devised, the collected plastic solid waste remains to be dealt with. Many methods of recycling plastics have been developed (Figure 2), some of which are summarized in a review paper by Al-Salem et al. (2010) and recounted below.

- Re-extrusion (primary recycling): Plastic solid waste of sizes between 2 and $4 \mathrm{~cm}$ is grinded, melted and formed to plastic resin pellets, which are subsequently used for manufacturing. An obstacle for this is that the plastic waste needs to be semi-clean to avoid contaminating the plastic, which would produce plastic resin of lower quality. For this reason, it is an unpopular choice for recycling, and mostly used within industries where clean plastic waste or leftovers are byproducts of manufacturing.

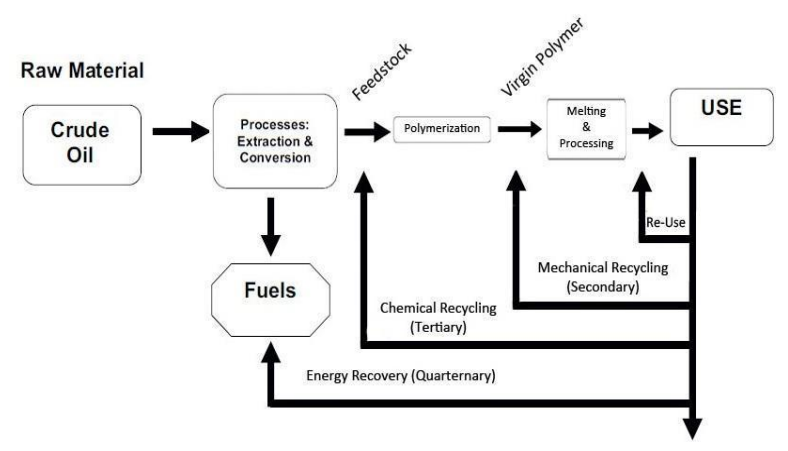

Figure 2. The different processes in plastic recycling. Adapted from Al-Salem et al. (2010).

- Mechanical recycling (secondary recycling): Plastic solid waste is sorted according to plastic type, then shredded, separated, washed and re-extruded. This approach allows for dirtier plastics to be recycled. However, as this recycling only is applicable for single-polymer plastics it gets gradually harder to apply mechanical recycling with increased complexity and contamination of the plastic waste. The heterogeneity and degradation of the plastics are major concerns, with low quality of the products as a result. 
- Chemical recycling (tertiary recycling): The most diverse form of plastic recycling. Simplified, it's the conversion of polymers to monomers and/or petrochemicals. These are then used as feedstock for polymerization, which in turn produces virgin resin. The three major groups or chemical recycling are pyrolysis, gasification and hydrogenation. The generalized forms of these processes will be explained below, along with their byproducts, but many variations of these processes exist or are in development.

- Pyrolysis is a process in which plastic solid waste is heated in an inert atmosphere to avoid combustion. Besides monomers, pyrolysis may create various products depending on which kind of waste is used, but some of the products are gases, tar and char. The gases are mostly high caloric, meaning they can be used for e.g. gas engines; the tar is waxes and highly aromatic liquids, and the chars are black coal or activated coal, which will contain the minerals from the waste.

- Gasification is a variety of pyrolysis in which organic waste is heated in air without combustion. This produces high colorific fuel gases and a large amount of char without the expenses associated with using pure oxygen. However, the presence of inert nitrogen gas will cause dilution of the fuel gases, so steam needs to be added in a stoichiometric ratio to reduce the presence of nitrogen gas. The char produced in the pyrolysis stage will be combusted in a second gasification chamber, which runs an equilibrium reaction of water + carbon monoxide to carbon dioxide + hydrogen.

- Hydrogenation is another variety of the pyrolysis process in which hydrogen gas is added to the reaction, creating hydrogen chloride as it reacts with chlorine from the plastic solid waste. This cleanses the gas and condensate products of chlorine contamination, meaning higher quality products free from chlorine is produced compared to other methods, when using chlorine-contaminated plastic solid waste. However, the hydrogenation process is very expensive and the profitability of the processes is not high enough to warrant use in most instances, hence many projects have been terminated.

- Energy recovery (quaternary recovery): The final resort is to incinerate the plastic solid waste. This won't produce any monomers, but it will produce heat, steam or energy. In this process incomplete incineration is a major problem, which produces many persistent organic pollutants, for example dioxins (Kim et al., 2008) and polycyclic aromatic hydrocarbons (Li et al., 2001) as byproducts. This leads to demands of high cost pollution control, reducing any profits.

Overall, research and development in the plastic industry is very active and the future will likely solve some of the problems these methods are currently facing, such as profitability. The chemical recycling of plastics can be very profitable (Al-Salem et al., 2010), so there is much incentive to further develop the methods.

\subsection{Increasing production of biodegradable plastics}

Biodegradable and photodegradable plastic production could be a good solution to the problem of marine plastic debris (Wolf and Feldman, 1991, Gorman, 1993). Biodegradable plastics are produced extensively, but petroleum based plastic products are cheap and easily produced which make them more profitable. Bioplastic is not widely used, in part because the application field is limited. Because bioplastics are made to be biodegradable, they are not suitable for long-term use in electronics or in construction materials. Unlikely petroleum plastics, bioplastics are not good enough to satisfy our need for food packaging material either, as their attributes when it comes to gas permeability, durability and resistance are not good enough. If the quality is improved and bioplastics could be used for food packaging or in other fields, it would likely reduce the need for petroleum plastics (Bio intelligence service, 2002).

\subsection{Enforcement of legislation and management}

Some management work for conservation of the marine environment has been conducted. The 1978 protocol MARPOL addresses the most important aspects of legislation for prevention of marine pollution from plastic products and oil (Lentz, 1987). Annex V of MARPOL is the key international legislation for controlling ship based sources of marine plastic debris (Ninaber, 1997). It highly restricts discharges of plastic material in to the ocean and performs good action for sea vessels that contains plastics and marine environment hazardous materials. Annex V also contains restrictions for recreational vessels (Nee, 1990). In 2002, 79 countries and special areas were under Annex V legislation (CMC, 2002).

However, the legislation is widely ignored and ships are still discharging large amounts of plastics into the ocean - as much as 6.5 million tons per year (Clark, 1997) and surveys showed no reduction in plastic accumulation at sea or reduced entanglement of marine animals as a result of Annex V (Henderson, 2001). Legislation thus needs to be strengthened, and may need to be forcefully applied to target groups in a way that is coordinated nationally and internationally (Derraik, 2002). 


\section{Recommendations}

The oceans cover over $70 \%$ of our planet but still most studies are conducted in the terrestrial system and marine biodiversity studies have been lagged behind (Murphy and Duffus, 1996). Lack of studies and less knowledge poses major problems for conservation of marine ecosystem. There is plenty of evidence, presented in the present report, that plastic pollution is a great threat to marine ecosystems, especially as it is already at risk for overfishing, climate change and other forms of anthropogenic disturbances (Derraik, 2002).

Plastic pollution should be addressed as a global problem. The buoyant plastic material can disperse long distances by wind driven circulation and water currents and, as mentioned before, plastic degrades very slowly in the ocean (Andrady, 1990; US EPA, 1992), leading to an accumulation of large aggregations of plastic debris at sea. As a result, even if plastic usage would be reduced throughout the world, the existing debris would continue to harm marine life for many decades. So, for the purpose of marine life conservation, the existing plastic debris in the marine systems should be removed.

More research efforts are crucial and longtime monitoring is necessary to quantify the actual threat of plastic debris, and to identify the hotspots for clean-up operations. Better data could introduce new and stricter conservation policies, better legislation, and raised awareness about marine plastic debris' harmful effect, thus strengthening the basis for education campaigns. Moreover, the research platform would guide researchers to propose possible solutions and thus, national and international organizations and authorities would come into discussion for providing help to mitigate the problem.

Annex V of MARPOL is the key international authority for controlling ship sources of marine debris (Ninebar, 1997) and came into effect in 1988 (Clark, 1997). The International Council of Cruise Lines brought in mandatory standards for cruise ships in 2001, which committed them to a policy goal of zero discharges according to MARPOL Annex V (Sheavly, 2005). This is to be achieved by using comprehensive waste minimization practices, and re-use and recycling waste strategies (UNEP 2005). Fact is that legislation is widely ignored in many areas due to lack of necessary control steps. 79 countries have so far ratified Annex V, but more countries need to be included in the efforts for constructive conservation policy. Focus in recruitment should be on developing countries, as their search for high economic growth cause high pressure to the environment.

Media plays a large role in raising awareness, and more educational campaigns as well as national and international conservation policies are needed for local nature conservation. A combination of better legislation and increased awareness has been suggested as a good way to mitigate the problems (Derraik, 2002). Local authorities, non-government organizations and volunteers have to work together to coordinate mitigation actions. Though the cost of beach clean-up is high, raising awareness of plastic pollution might result in more volunteer workers. A 'beach clean-up day' is a simple way to combine mitigative actions and raising awareness. The global clean-up program 'clean up the world', which is run in conjunction with UNEP, engages more than 40 million people from 120 different countries in clean-up operations, and has a special initiative for marine debris (UNEP, 2005). 'Clean up Australia day' is another example that has been very successful in helping to clean up beaches of Australia. Thus, thinking globally and acting locally remains a good approach.

\section{Conclusions}

In conclusion, as land based sources of marine debris make up $80 \%$ of total releases (Sheavly, 2005), educating communities about the problems of marine plastic debris may help to reduce pollution. Education in schools increases awareness in young children, who may spread the knowledge to their friends and family. Thus, educating communities is also an attractive and effective way to reduce the extent of land based plastic debris sources.

\section{Conflict of interest}

None to declare.

\section{References}

Allsopp M, A Walters, D Santillo and P Johnston, 2006. Plastic Debris in the World's Oceans. 43p., Greenpeace, Amsterdam, Netherlands.

Al-Salem SM, P Lettieri and J Baeyens, 2010. The valorization of plastic solid waste (PSW) by primary to quaternary routes: From re-use to energy and chemicals. Progress in Energy and Combustion Science., 36: $103-129$.

Aliani S and A Molcard, 2003. Hitch-hiking on floating marine debris: macrobenthic species in the Western Mediterranean Sea. Hydrobiologia, 503: 59-67. 
Azzarello MY and ES Van Vleet, 1987. Marine birds and plastic pollution. Mar. Ecol. Prog. Ser., 37: 295-303.

Baird RW and SK Hooker, 2000. Ingestion of Plastic and Unusual Prey by a Juvenile Harbour Porpoise. Marine Pollution Bulletin.

Barnes DKA and P Milner, 2005. Drifting plastic and its consequences for sessile organism dispersal in the Atlantic Ocean. Marine Biology, 146: 815-825.

Bax N, A Williamson, M Aguero, E Gonzalez and W Geeves, 2003. Marine invasive alien species: a threat to global biodiversity. Marine Policy, 27: 313-323.

Bio Intelligence service, European Union 2011. Plastic pollution in the environment.

Bjorndal KA, AB Bolten and CJ Lagueux, 1994. Ingestion of Marine Debris by Juvenile Sea Turtles in Coastal Florida Habitats. Marine Pollution Bulletin, 28: 154-158.

Blight LK and AE Burger, 1997. Occurrence of Plastic Particles in Seabirds from the Eastern North Pacific. Marine Pollution Bulletin, 34: 323-325.

Boerger CM, GL Lattin, SL Moore and CJ Moore, 2010. Plastic ingestion by planktivorous fishes in the North Pacific Central Gyre. Marine Pollution Bulletin, 60: 2275-2278.

Breen PA, 1990. A review of ghost fishing by traps and gill nets. Proceedings of the Second International Conference on Marine Debris, 2-7 April 1989.

Cawthorn M, 1989. Impacts of marine debris on wildlife in New Zealand coastal waters. In: Proceedings of Marine Debris in New Zealand's Coastal Waters Workshop, 9 March 1989, Wellington, New Zealand. Department of Conservation, Wellington, New Zealand, pp. 5-6.

Clark RB, 1997. Marine Pollution. Clarendon Press, Oxford.CMC-Center for Marine Conservation, 2002.

Derraik JGB, 2002. The pollution of the marine environment by plastic debris: a review. Marine Pollution Bulletin, 44: 842-852.

Eriksson $\mathrm{C}$ and $\mathrm{H}$ Burton, 2003. Origins and biological accumulation of small plastic particles in fur seals from Macquarie Island. Ambio, 32: 380-384.

Feldkamp SD, DP Costa and GK DeKrey, 1989. Energetic and behavioral effects of net entanglement on juvenile northern fur seals, Callorhinus ursinus. Fishery Bulletin, 87: 85-94.

Gorman M, 1993. Environmental Hazards-Marine Pollution. ABCCLIO Inc, Santa Barbara.

Graham ER and Thompson JT, 2009. Deposit- and suspension-feeding sea cucumbers (Echinodermata) ingest plastic fragments. Journal of Experimental Marine Biology and Ecology, 368: 22-29.

Gregory MR, 1978. Accumulation and distribution of virgin plastic granules on New Zealand beaches. New Zealand Journal of Marine and Freshwater Research, 12: 399-414.

Gregory MR, 1989. Accumulation of plastic debris in New Zealand's coastal waters and exclusive economic zone. In: Proceedings of Marine Debris in New Zealand's Coastal Waters Workshop, 9 March 1989, Wellington, New Zealand. Department of Conservation, Wellington, New Zealand, pp. 3-4.

Kim SH, S Ahn and S Kwak, 2008. Suppression of dioxin emission in incineration of poly vinyl chloride (PVC) as hybridized with titanium dioxide (TiO2) nanoparticles. Applied Catalysis B: Environmental, 79: 296-305.

Lentz SA, 1987. Plastics in the marine environment: legal approaches for international action. Marine Pollution Bulletin, 18, 361-365.

Li C, H Zhuang, L Hsieh, W Lee and M Tsao, 2001. PAH emission from the incineration of three plastic wastes. Environment International, 27: 61-67.

Lobelle D and M Cunliffe, 2001. Early Microbial Biofilm Formation on Marine Plastic Waste. Marine Pollution Bulletin, 62: 197-200.

Moore E, S Lyday, J Roletto, K Litle, JK Parrish, H Nevins, J Harvey, J Mortenson, D Greig, M Piazza, A Hermance, D Lee, D Adams, S Allen and S Kell, 2009. Entanglements of marine mammals and seabirds in central California and the north-west coast of the United States 2001-2005. Marine Pollution Bulletin, 58: 1045-1051.

Murphy DD and DA Duffus, 1996. Conservation biology and marine biodiversity. Conservation Biology, 10: 311-312.

Ninaber E, 1997. MARPOL Annex V, commercial ships, and port reception facilities: making it work. In: Coe, J.M., Rogers, D.B. (Eds.), Marine Debris-Sources, Impacts and Solutions. Springer- Verlag, New York., 239-243.

O'Hara K, S Iudicello and R Bierce, 1988. A Citizen's Guide to Plastics in the Ocean: More than a Litter Problem. Center for Marine Conservation, Washington DC.

Raum-Suryan KL, LA Jemison and KW Pitcher, 2009. Entanglement of Steller sea lions (Eumetopias jubatus) in marine debris: Identifying causes and finding solutions. Marine Pollution Bulletin, 58: 1487-1495. 
Redford DP, HK Trulli and WR Trulli, 1997. Sources of plastic pellets in the aquatic environment. In: Coe, J.M., Rogers, D.B. (Eds.), Marine Debris-Sources, Impacts and Solutions. Springer- Verlag, New York., 335-343.

Ryan PG, AD Connell and BD Gardner, 1998a. Plastic Ingestion and PCBs in Seabirds: Is There a Relationship? Marine Pollution Bulletin, 19:174-176.

Ryan PG, 1998b. Effects of Ingested Plastic on Seabird Feeding: Evidence from Chickens. Marine Pollution Bulletin, 19: 125-128.

Secchi ER and S Zarzur, 1999. Plastic debris ingested by a Blainville's beaked whale, Mesoplodon densirostris, washed ashore in Brazil. Aquatic Mammals, 25: 21-24.

Schrey E and GIM Vauk, 1987. Records of Entangled Gannets (Sula bassana) at Helgoland, German Bight. Marine Pollution Bulletin, 18: 350-352.

Sheavly SB, 2005. Sixth Meeting of the UN Open-ended Informal Consultative Processes on Oceans \& the Law of the Sea. Marine debris - an overview of a critical issue for our oceans. June 6-10.

Shiber JG, 1979. Plastic pellets on the coast of Lebanon. Marine Pollution Bulletin, 10: 28-30.

Shiber JG, 1982. Plastic pellets on Spain's 'Costa del Sol' beaches. Marine Pollution Bulletin, 13: 409-412.

Shiber JG, 1987. Plastic pellets and tar on Spain's Mediterranean beaches. Marine Pollution Bulletin, 18: 84-86.

Teuten EL, SJ Rowland, TS Galloway and RC Thompson, 2007. Potential for Plastics to Transport Hydrophobic Contaminants. Environ. Sci. Technol., 41: 7759-7764.

Thiel M, I Hinojosa, N Vásquez. and E Macaya, 2003. Floating marine debris in coastal waters of the SEPacific (Chile). Marine Pollution Bulletin, 46: 224-231.

Tomás J, R Guitart, R Mateo and JA Ragaa, 2002. Marine debris ingestion in loggerhead sea turtles, Caretta caretta, from the Western Mediterranean. Marine Pollution Bulletin, 44: 211-216.

Uneputty P and SM Evans, 1997. The impact of plastic debris on the biota of tidal flats in Ambon Bay (Eastern Indonesia). Marine Environmental Research, 44: 233-242.

UNEP, 1999. Assessment of land-based sources and activities affecting the marine, coastal and associated freshwater environment in the south-east pacific. UNEP/GPA Coordination Office \& CPPS., 73.

UNEP, Plastic debris in the world's oceans, 1997. Available at: http://www.unep.org/regionalseas/ marinelitter/publications/docs/plastic_ocean_report.pdf

UNESCO, 1994. Marine Debris: Solid Waste Management Action Plan for the Wider Caribbean. IOC Technical Series 41, Paris.

Votier SC, K Archibald, G Morgan and L Morgan, 2011. The use of plastic debris as nesting material by a colonial seabird and associated entanglement mortality. Marine Pollution Bulletin, 62: 168-172.

Wolf N and E Feldman, 1991. Plastics-America's packaging dilemma. Environmental Action Coalition. Island Press, Washington DC. 